\section{Cell and tissue proteinases}

Proteinases in Mammalian Cells and Tissues. Edited by A. J. Barrett. Pp. xx +735. (North-Holland: New York, Oxford and Amsterdam, 1977.) Dfl. 196; $\$ 79.95$.

THE scope of this long and expensive book is somewhat wider than is indicated by its title because two of its sixteen chapters deal with proteinase inhibitors and another is devoted to synthetic substrates and inhibitors. In addition, the properties of the plasminogen activators of plasma, tissue and urine are described in an interesting chapter by Christman, Silverstein and Acs, who emphasise that neither the source of the plasminogen activators of the plasma, nor the identity of these enzymes with thier tissue counterparts, can be stated with certainty.

Evidently, it is difficult to decide on all the enzymes which should be considered to be either cell or tissue proteinases. Undoubtedly, however, the decision to include consideration of certain plasma constituents has proved fruitful because, without data of this kind, discussion of the physiological roles of the cell and tissue proteinases would be difficult. The discussion of some aspects of how the tissue proteinases may be expected to function in vivo, such as whether plasminogen activators are important in tumorigenisis and wound healing, is speculative, but the inclusion of these concepts adds greatly to the interest of the book.

The rapidity at which information on tissue proteinases has accumulated since 1975 is mentioned in the preface. It is indeed remarkable that, whereas only six enzymes were dealt with in a similar book published in that year, details of seventy-one are to be found in the present volume. The introductory chapter by Barrett on the history and classification of the tissue proteinases helps to clarify the subject. By way of an extra, it is interesting to learn that Darwin in 1875 was the first to pose the question of the evolutionary relationship of the proteinases of plants and animals.

Perhaps because of the importance of elastase and Cathepsin $\mathrm{G}$ in inflammation the first chapter by Starkey is devoted to the methods of isolation and properties of these two enzymes which together have been shown to be capable of hydrolysing all the major tissue proteins. Particularly when extracellular (as, for instance, at the start of inflammation and thus not subject to the same degree of inhibition by $\alpha_{2}$ macroglobulin or $\alpha_{1}$ antitrypsin), these enzymes have been shown to be capable of digesting immune complexes and probably of playing a part in combating bacterial infection. These findings are mentioned mainly as an example of the mass of detailed information which has been brought together in this book. Undoubtedly the efforts of the many contributors have resulted in a volume which is both stimulating and will remain as a useful source book.

It is a pleasure to be able to report that there are few errors: in fact only one of any importance has been detected by the reviewer. This concerns the $\alpha_{1}$ and $\alpha_{2}$ macroglobulins of rabbit and rat. Unfortunately on p670, lines 7 and 8 , the subscripts have been transposed. This is of some importance because as printed the impression is

given that $\alpha_{2}$ macroglobulin of rabbit and $\alpha_{1}$ macroglobulin of rat increase in concentration during inflammation. In fact, it is the other way round.

It will be an added recommendation to potential readers that more than half of the chapters have been written either by the editor himself or by other members of the staff of the Strangeways Laboratory. In an important sense, the appearance of this volume will make more easily available much of the research on tissue proteinases for which the Strangeways has become an acknowledged centre.

A. H. Gordon

\section{Asymmetric reactions}

Stereo-Differentiating Reactions: The Nature of Asymmetric Reaction. By Yoshiharu Izumi and Akira Tai. P. ix + 334. (Kodansha/Academic: Tokyo, New York and London, 1977.) $\$ 29.50 ; £ 20.95$.

From the introduction, it would seem that this book has two main aims: (1) to provide an introductory text with the basic physics and mathematics appropriate to asymmetric reactions; and (2) to present a new system of classification of asymmetric reactions developed by the authors and previously published in Japanese. One wonders what kind of reader the authors had in mind, since they have written a book which anyone unfamiliar with the field would have considerable difficulty in following and and which therefore cannot be regarded as an introductory text. A research worker interested in the mechanism of asymmetric reactions, on the other hand, will hardly want a research monograph to contain a chapter "Basic Principle of Optical Activity" or even one on experimental methods.

The key chapters are those in which the authors give their new nomenclature and classification. The authors' exposition is sometimes difficult to follow. They write: "A stereoselective reaction is defined as one in which one specific stereoisomer is produced to a greater extent than the other", but give as an example, the conversion of maleic and fumaric acids to maleic anhydride! They then go on to introduce terms like enantiozeroplane, enantiotopos, enantioface, or diastereotopos-differentiating reaction, and the reader is bound to wonder if these terms are necessary. Are they really useful? Does their use clarify problems in reaction mechanisms?

The new classification with six reaction types could have some advantages when considering mechanistic problems. The chapters which discuss these in detail, and which form the bulk of the book are, however, disappointing. They contain a mass of information about organic reactions and about mechanisms proposed in the literature. The extensive discussion of the authors' own work on modified Raney nickel catalysts provides an interesting test case, and it must be said that nothing has been written which could not have been written as clearly or indeed more clearly without recourse to their terms.

One is left with the feeling that the authors have made a brave effort to think about problems which are conceptually notoriously difficult, and that their ideas are not without value. Their own exposition, however, is unconvincing and it would have been far better to have written a much shorter book with fewer examples to try and make their concepts clear.

The occasional absence of the definite article indicates that the translator was Japanese; on the whole, the translation is good, but there are quite a lot of misprints. The index is inadequate; for example, one could not discover from it that Grignard reactions are twice discussed, the only entry being a subheading under "enantioface-differentiatỉng reaction".

T. L. V. Ulbricht

T. L. V. Ulbricht is Scientific Adviser (Special Duties) at the Agricultural Research Council, London, UK. 